\title{
Tailor-Made Silver Release Properties of Silver- Containing Functional Plasma Polymer Coatings Adjusted Through a Macroscopic Kinetics Approach
}

\author{
Enrico Körner • Barbara Hanselmann • Peter Cierniak • \\ Dirk Hegemann
}

Received: 8 November 2011/Accepted: 23 February 2012/Published online: 7 March 2012

(C) Springer Science+Business Media, LLC 2012

\begin{abstract}
Combining a functional plasma polymer matrix with antibacterially active silver (Ag) within a nanocomposite structure allows secure production and applications in various fields, especially in the medical sector. Therefore, nitrogen or oxygen containing hydrocarbon plasma polymers and $\mathrm{Ag}$ nanoparticles were simultaneously deposited. Functional groups such as amino or carboxylic groups as well as an adjusted amount of Ag can be incorporated into the growing films by controlling the plasma deposition properties. For this purpose, macroscopic kinetics were used to characterise the deposition behaviour also as a base for possible industrial up-scaling. XPS and ICP-OES were used to analyse the chemical composition of the polymer-Ag nanocomposites and the Ag content which could be incorporated depending on the plasma process conditions. Finally, the Ag release was determined in bi-distilled water for classification and comparison with the antibacterial properties. The antibacterial effect of the polymer-Ag nanocomposites was proofed with the gram- strain Pseudomonas aeruginosa PAO1 and the gram + strain Staphylococcus aureus (ST12 Group) showing a clear efficacy dependence on the amount of released Ag and the possibility for tailor-made antibacterial active plasma films.
\end{abstract}

Keywords Plasma polymerisation $\cdot$ Sputtering $\cdot$ Nanocomposite $\cdot$ Macroscopic kinetics · Antibacterial

\section{Introduction}

Nanoparticles or nanocomposite films, containing e.g. silver (Ag) [1, 2] or copper [3], are widely investigated for biomedical applications or antibacterial products [4]. Different to copper or nickel, silver shows no allergisation potential in contact with human skin.

\footnotetext{
E. Körner $(\bowtie) \cdot$ B. Hanselmann · D. Hegemann

Empa, Swiss Federal Laboratories for Materials Science and Technology,

Lerchenfeldstrasse 5, 9014 St. Gallen, Switzerland

e-mail: enrico.koerner@empa.ch

P. Cierniak

Medical Faculty, Institute of Legal Medicine, University of Cologne,

Melatengürtel 60-62, 50823 Cologne, Germany
} 
Different production strategies are under research in order to combine antibacterially active $\mathrm{Ag}$ containing treatments with multifunctional properties, such as the combination of antibacterial properties with a non-cytotoxic environment [5, 6]. Nano-scaled plasma films facilitate such properties even in industrially applicable processes [7]. Low pressure plasma polymerisation using a gas mixture of ethylene $\left(\mathrm{C}_{2} \mathrm{H}_{4}\right)$ with ammonia $\left(\mathrm{NH}_{3}\right)$ or carbon dioxide $\left(\mathrm{CO}_{2}\right)$ was shown to yield a cross-linked hydrocarbon polymer coating containing nitrogen or oxygen functionalities, respectively [8,9]. Simultaneous co-sputtering from a silver electrode with added argon gas supported in situ formation of $\mathrm{Ag}$ nanoparticles within the growing plasma polymer [10-13].

The deposition behaviour of plasma polymer coatings as well as nanocomposite films can be analysed and classified using a macroscopic approach based on the specific energy input into the plasma process [14-16]. An Arrhenius relation can be used to describe the mass deposition rate per unit of gas flow $R_{m} / F$ with the specific energy input $W / F$ (power input per gas flow rate) as reaction parameter:

$$
\frac{R_{m}}{F}=G \exp \left(-\frac{E_{a}}{W / F}\right)
$$

where $E_{a}$ represents an apparent activation energy (activation barrier) and $G$ is a reactor and process dependent factor $[17,18]$. The total gas flow rate $F$ related to its contribution to film growth can be adjusted by adding the reactive gas flow rate $F_{c}$ with a flow (weighting) factor $a\left(\sim 0.5\right.$ for $\mathrm{NH}_{3} ; \sim 0.15$ for $\mathrm{CO}_{2} ; \sim 0.05$ for Ar) to the monomer flow $F_{m}$, which comprises the reactivity of the gas in the polymerisation process [15]. It was shown that the functionality of the plasma polymers was maintained within the valid range of (1) $[10,11,16]$. With the help of the macroscopic kinetics model, the film deposition can thus be adjusted having the required Ag content to be antibacterially active which can be confirmed by Ag release measurements.

A comparison of low pressure RF discharges (combination of PECVD and PVD) for the deposition of either nitrogen- or oxygen-functional polymer-Ag nanocomposites using gas ratios of $\mathrm{NH}_{3} / \mathrm{C}_{2} \mathrm{H}_{4}=1: 1$ and $\mathrm{CO}_{2} / \mathrm{C}_{2} \mathrm{H}_{4}=2: 1$ was carried out. The influence of the gas mixture and the power input on the deposition process was investigated with respect to the final Ag release for biomedical applications.

\section{Materials and Methods}

\section{Plasma Polymerisation and Co-sputtering}

An asymmetrically configured $13.56 \mathrm{MHz}$ radiofrequency (RF) driven plasma reactor was used to deposit the polymer-Ag nanocomposites. This setup included the powered Ag electrode $(\varnothing=16 \mathrm{~cm})$, mounted on the top inside the plasma reactor (insulated by a ceramic plate) and the counter electrode $(\varnothing=30 \mathrm{~cm})$ separated by a glass ring $(\varnothing=30 \mathrm{~cm}$, $\mathrm{h}=5 \mathrm{~cm}$ ). Due to the sputtering conditions in the asymmetrical setup, Ag atoms are released and incorporated during the plasma polymer growth forming Ag nanoparticles by surface diffusion and agglomeration. The process pressure was kept constant at $10 \mathrm{~Pa}$ to enable both plasma polymerisation and RF sputtering (as described in more detail elsewhere [11]).

\section{Deposition Rate}

The deposition rate was determined by weighing 10 thin glass substrates with a known size of $50 \mathrm{~mm} \times 24 \mathrm{~mm}$ each directly before and after the coating process with a Mettler AT 
261 Delta Range ${ }^{\circledR}$ balance (precision: $0.01 \mathrm{mg}$ ). The $\mathrm{CO}_{2} / \mathrm{C}_{2} \mathrm{H}_{4}$ coatings were deposited using an actual gas flow of $4 \mathrm{sccm} \mathrm{CO}$ and $2 \mathrm{sccm} \mathrm{C} \mathrm{C}_{2} \mathrm{H}_{4}$. For the $\mathrm{NH}_{3} / \mathrm{C}_{2} \mathrm{H}_{4}$ coatings a gas flow of $4 \mathrm{sccm}$ for both gases was used. The coatings deposited with the admixture of $\mathrm{Ar}$ were carried out with an additional flow rate of $50 \mathrm{sccm}$ Ar.

Inductively Coupled Plasma-Optical Emission Spectrometry

\section{Ag Content}

In order to determine the total Ag content of the coatings and Ag released into $4 \mathrm{ml}$ deionized water, inductively coupled plasma-optical emission spectrometry (ICP-OES) was performed on plasma-coated Petri dishes (only films deposited with additional Ar) using an Optima 3000 Perkin Elmer instrument. The obtained Ag amounts for both tests were given in $\mathrm{g} \mathrm{cm}^{-3}$ regarding the film thickness, which enable a good comparison with pure Ag $\left(10.49 \mathrm{~g} \mathrm{~cm}^{-3}\right)$.

\section{Ag Release}

The various coated dishes were exposed to $4 \mathrm{ml}$ of deionized water $(18 \mathrm{mV})$ at $37^{\circ} \mathrm{C}$ for a period of 1, 4, 6 and 14 days. The Ag-containing solution was then injected into the ICPOES and optically analysed (Ag lines 328.068 and $338.289 \mathrm{~nm}$ ).

\section{Transmission Electron Microscopy}

The polymer-Ag nanocomposite coatings on $\mathrm{Si}$ substrates were thinned in cross sectional view geometry with the tripod method. The final thickness suitable for electron transmission was achieved by an $\mathrm{Ar}^{+}$beam milling system (RES 101 from Baltec). Low and high-resolution transmission electron microscopy (HRTEM) were performed with a Philips CM30 and a Jeol JEM FS2200 microscope, respectively.

\section{X-ray Photoelectron Spectroscopy Analysis}

The chemical composition, especially the Ag of the coatings deposited with different plasma conditions were analysed by XPS measurements. A PHI 5600 LS equipped with a hemispherical electron analyser and an $\mathrm{Mg}-\mathrm{K} \alpha(300 \mathrm{~W}, 1253.6 \mathrm{eV}) \mathrm{X}$-ray source was used to analyse the samples using a base pressure of $10^{-6} \mathrm{~Pa}$. Survey and high resolution spectra were recorded using pass energies of 187.8 and $29.8 \mathrm{eV}$ and step widths of 0.400 and $0.125 \mathrm{eV}$, respectively. The calculation of the atomic concentration was performed with CasaXPS Version 2.3.12 software using the instrument specific sensitivity factors $0.314,0.499,0.733$, and 6.277 for $\mathrm{C} 1 \mathrm{~s}, \mathrm{~N} 1 \mathrm{~s}, \mathrm{O} 1 \mathrm{~s}$, and $\mathrm{Ag} 3 \mathrm{~d}$, respectively. The carbon $\mathrm{C} 1 \mathrm{~s}(\mathrm{C}-\mathrm{C})$ binding energy was determined by measurement of the adventitious carbon on a pure gold coating and set to $284.5 \mathrm{eV}$. The background subtraction was performed using the Shirley approach.

\section{Antibacterial Activity Tests}

The samples were tested against a Pseudomonas aeruginosa PAO1 and an isolate of Staphylococcus aureus classified into the MLST group 12 (ST12). The testing was performed as follows: cultures of both strains were grown in tubes containing $6 \mathrm{ml}$ of Lysogeny Broth (LB) (Carl Roth, Karlsruhe, Germany) at $37^{\circ} \mathrm{C} / 170 \mathrm{rpm}$ for $18 \mathrm{~h}$. An aliquot of $1 \mathrm{ml}$ 
was taken from these cultures and centrifuged at $5.000 \mathrm{~g}$ for $3 \mathrm{~min}$ at RT (Biofuge Primo R, Thermo Fisher Scientific Germany Ltd. \& Co. KG, Braunschweig, Germany). Afterwards the aliquot was resuspended and diluted in 1:10 LB medium (dilution in sterile distilled water). The initial bacterial concentration in the Petri dishes (Bibby Sterilin Ltd., Stone, Staffs, UK) was for both strains between $2 \times 10^{4}$ and $6 \times 10^{4}$ Colony Forming Units (CFU) $\mathrm{ml}^{-1}$. Valuable cell number was determined by viable cell count and correlated to photometer measurements at $600 \mathrm{~nm}$ (Genesys UV 10, Thermo Fisher Scientific Germany Ltd. \& Co. KG, Braunschweig, Germany). Coatings were tested by growing bacteria on plasma polymer coated $50 \mathrm{~mm}$ Petri dishes containing $4 \mathrm{ml}$ of 1:10 LB medium. The Petri dishes were statically incubated at $37^{\circ} \mathrm{C}$ for $20-24 \mathrm{~h}$. After the incubation period the suspensions were serially diluted and a viable cell count was prepared on LB-Agar plates. Agar plates were incubated for $24 \mathrm{~h}$. As control, uncoated Petri dishes were used as well as Petri dishes that were plasma-coated lacking silver. Each parameter was tested in duplex or triplicate, for each repetition a separate bacterial culture was prepared. Only those plates that showed 30-350 colonies were counted.

\section{Results and Discussion}

The distribution of the $\mathrm{Ag}$ nanoparticles in a $100 \mathrm{~nm}$ thick functional plasma polymer matrix is shown exemplarily in Fig. 1 for the $\mathrm{CO}_{2} / \mathrm{C}_{2} \mathrm{H}_{4}$ coating, which is in good

Fig. 1 TEM cross section image of a nanocomposite deposited from $\mathrm{CO}_{2} / \mathrm{C}_{2} \mathrm{H}_{4}$

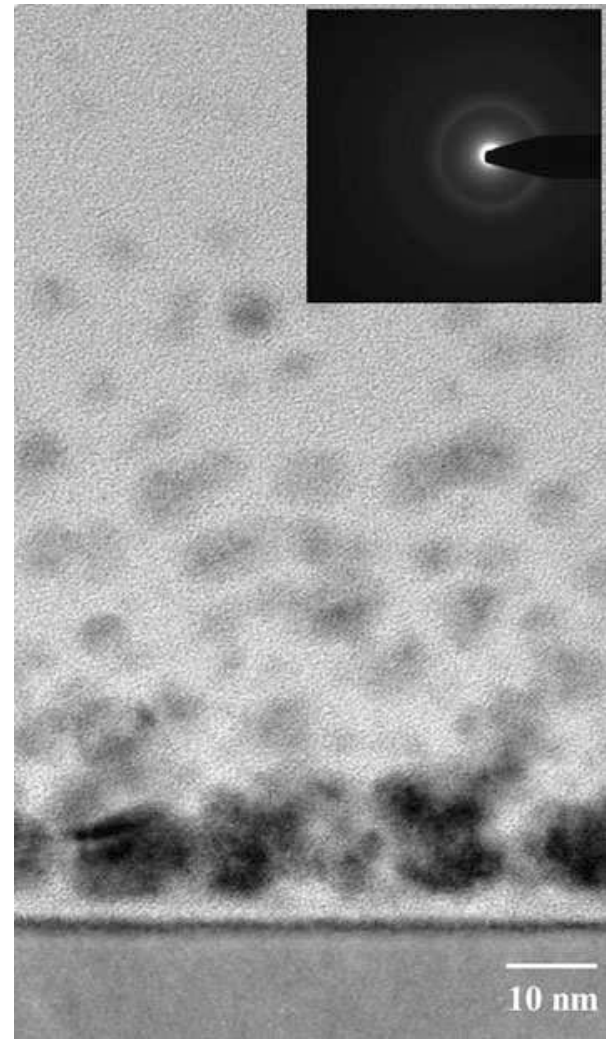


agreement with the $\mathrm{NH}_{3} / \mathrm{CO}_{2}$ coatings [19]. The high agglomeration of $\mathrm{Ag}$ in the first $10 \mathrm{~nm}$ was found to be caused by the initial process conditions enabling a higher Ag sputtering rate [12] and by metal agglomeration at interfaces [20]. An increasing coating thickness above $10-15 \mathrm{~nm}$ (increasing process duration) resulted in more randomly distributed Ag nanoparticles within the hydrocarbon matrix with a lower metal volume filling factor [21].

Changes of the deposition rates of coatings produced with a gas ratio $\mathrm{NH}_{3} / \mathrm{C}_{2} \mathrm{H}_{4}$ of $1: 1$ and $\mathrm{CO}_{2} / \mathrm{C}_{2} \mathrm{H}_{4}$ of 2:1 were analysed using an Arrhenius-type plot showing the dependence on power input per flow rate W/F (Fig. 2). The incorporation of $\mathrm{Ag}$ (nanoparticles) into the growing functional hydrocarbon matrix can be obtained for higher energy inputs (regime II) as indicated by the strongly increasing deposited mass (as compared to an Arrhenius behaviour). The increase in Ag content was proofed with ICP-OES analyses of the films, where an increasing power input yielded a higher Ag (nanoparticle) content (Fig. 3). The coatings deposited with a low energy input (regime I in Fig. 2) show a linear range in the Arrhenius-type plot indicating a dominance of plasma polymerisation processes [15] and very low Ag sputtering rates [11]. The coatings referring to the linear range contain only a minimum of $\mathrm{Ag}$ up to no detectable $\mathrm{Ag}$. The clear differences of the $\mathrm{Ag}$ content in the dependence of the power input of both gas mixtures points towards a reduced Ag sputtering rate within an oxygen containing plasma. The finding of a decrease of the deposited mass with Ar admixture (Fig. 2) might be related to a limitation by surface reactions on the grounded electrode due to a reduced residence time at higher total gas flow [22]. However, the Ag sputtering rate was increased due to the admixture of Ar, which can already be seen by the decrease in difference between the deposition rates in regime II with and without Ar (Fig. 2). Therefore, Ar admixture was used for the following investigations.

The Ag release might not only be controlled by the Ag content. The chemical composition of the coatings and the crosslinking of the polymer matrix will also influence the effective Ag release. More cross-linked plasma polymers comprise less polar groups and voids, thus reducing their water uptake. Finally, this will affect the oxidation of the Ag nanoparticles and ion exchange properties of the polymer-Ag nanocomposite coatings [23] according to the formula:

$$
\mathrm{O}_{2(\mathrm{aq})}+4 \mathrm{H}_{3} \mathrm{O}^{+}+4 \mathrm{Ag}^{(0)}=4 \mathrm{Ag}_{(\mathrm{aq})}^{+}+6 \mathrm{H}_{2} \mathrm{O}
$$

The atomic percentage of Ag increases with increasing power input (Table 1) which could be already detected by the use of ICP-OES. The incorporation of nitrogen and

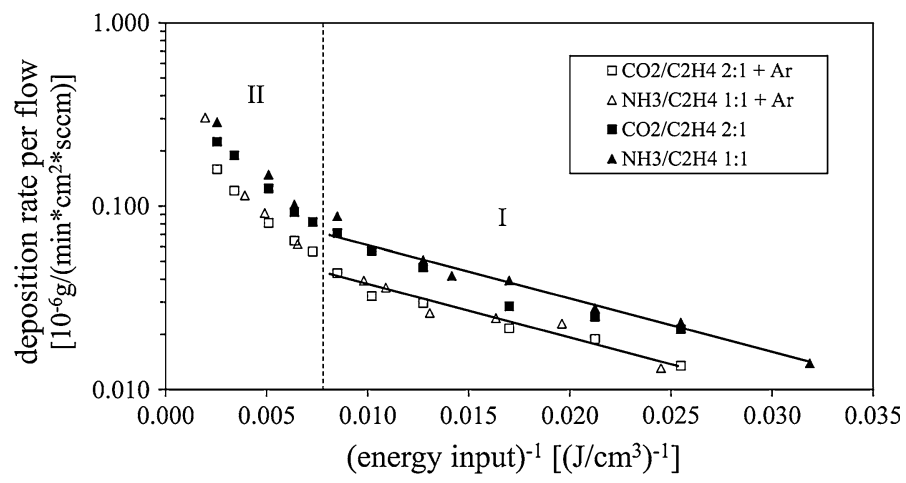

Fig. 2 Mass deposition rates of $\mathrm{NH}_{3} / \mathrm{C}_{2} \mathrm{H}_{4}=1: 1$ and $\mathrm{CO}_{2} / \mathrm{C}_{2} \mathrm{H}_{4}=2: 1$ with and without Ar plotted against $(W / F)^{-1}$ 


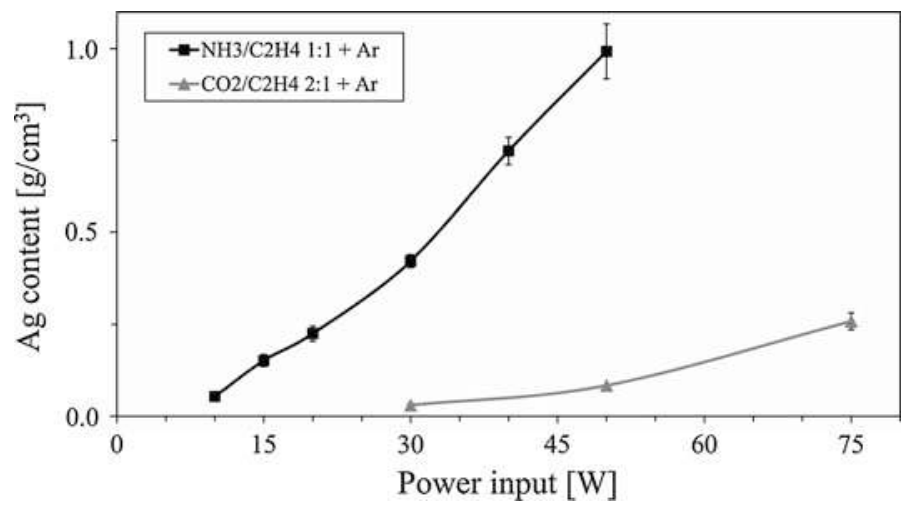

Fig. $3 \mathrm{Ag}$ content of $100 \mathrm{~nm}$ thick polymer-Ag nanocomposites

Table 1 Chemical composition of the polymer-Ag nanocomposite coatings measured with XPS

\begin{tabular}{lllll}
\hline & Power $(\mathrm{W})$ & $\mathrm{C} 1 \mathrm{~s}($ at $\%)$ & O1s (at $\%)$ & Ag3d (at $)$ \\
\hline $\mathrm{CO}_{2} / \mathrm{C}_{2} \mathrm{H}_{4}$ ratio & & & & \\
$2: 1$ & 30 & 74.1 & 25.5 & 0.4 \\
& 50 & 75.7 & 23.5 & 0.8 \\
& 75 & 75.9 & 22.3 & 1.8 \\
$\mathrm{NH}_{3} / \mathrm{C}_{2} \mathrm{H}_{4}$ ratio & & & & \\
$1: 1$ & 10 & 82.4 & 16.6 & 1.0 \\
& 20 & 80.3 & 17.6 & 2.1 \\
& 30 & 78.8 & 18.2 & 3.0 \\
& 50 & 78.6 & 17.7 & 3.7 \\
\hline
\end{tabular}

oxygen in the polymer matrix was found to be (more or less) independent of power input at constant gas ratio as could be expected for the Arrhenius regime. Increasing ion bombardment, however, can favour the production of more cross-linked coatings [24]. Since XPS is a surface sensitive method (penetration depth up to $5 \mathrm{~nm}$ ), whereas ICP-OES includes the whole film, small deviations (in Ag content) can occur between both analysis methods.

Finally, the Ag release was determined indicating a clear dependence on the incorporated $\mathrm{Ag}$ content. The same Ag release behaviour was observed for the coatings produced with the $\mathrm{NH}_{3} / \mathrm{C}_{2} \mathrm{H}_{4}$ gas ratio $1: 1$ and $10 \mathrm{~W}$ power input and the oxygen containing coating $\left(\mathrm{CO}_{2} / \mathrm{C}_{2} \mathrm{H}_{4}=2: 1\right)$ produced with $30 \mathrm{~W}$. These coatings contain approximately the same (low) Ag content (Fig. 3). A higher Ag release was obtained for the coatings produced with a higher power input (Fig. 4). A more continuous $\mathrm{Ag}$ release was found for the $\mathrm{CO}_{2} / \mathrm{C}_{2} \mathrm{H}_{4}$ coatings produced with $75 \mathrm{~W}$, whereas the $\mathrm{NH}_{3} / \mathrm{C}_{2} \mathrm{H}_{4}-30 \mathrm{~W}$ coating showed an initial $\mathrm{Ag}$ release boost [19]. This indicates differences in the matrix structure and density. Coatings deposited with the $\mathrm{NH}_{3} / \mathrm{C}_{2} \mathrm{H}_{4}$ gas ratio of 1:1 appear to be nanoporous as illustrated by the low film density between 1.2 and $1.3 \mathrm{~g} \mathrm{~cm}^{-3}$ [25]. The lower chemically induced etching effects of $\mathrm{CO}_{2}$ compared to $\mathrm{NH}_{3}$ [15] and the increased polymer crosslinking due to the high power input of $75 \mathrm{~W}$ (higher ion bombardment) led to a higher film density of $1.4-1.5 \mathrm{~g} \mathrm{~cm}^{-3}$ of the oxygen containing coatings [17]. The decrease in the Ag release 


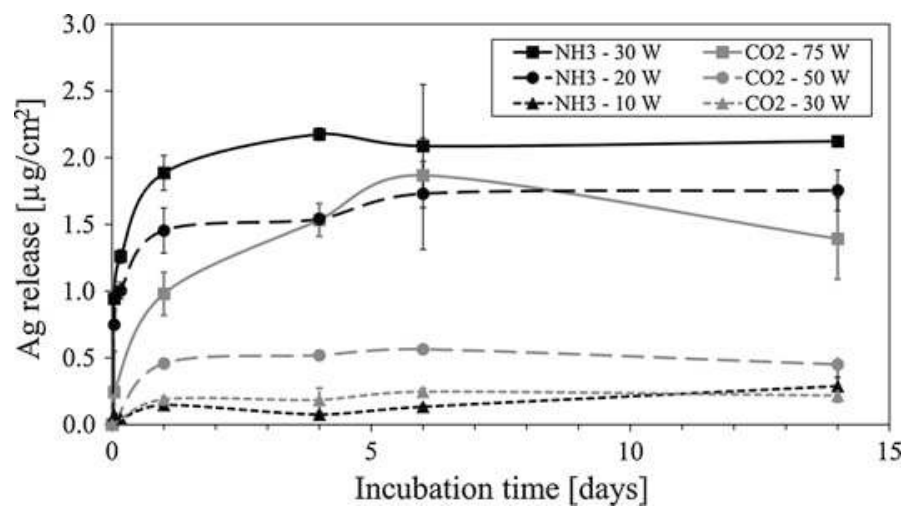

Fig. 4 Ag release from $100 \mathrm{~nm}$ thick polymer-Ag nanocomposites with $\mathrm{Ar}$

values between the 6th and 14th day of the coating produced with $75 \mathrm{~W}$ could be due to a redeposition of the released $\mathrm{Ag}$ because of the static conditions of the cumulative test method. In general, the $\mathrm{Ag}$ release values of the polymer-Ag nanocomposites can be adjusted by the examined process parameters gas ratio and energy input over a broad range of antibacterial requirements. The Ag release values of the polymer-Ag nanocomposite coatings are in good agreement with other studies using other silver doped materials [26], other test solutions [27] or temperatures [28].

These multifunctional polymer-Ag nanocomposites were tested with gram + and gram- bacteria resulting in highly antibacterially active coatings (Fig. 5), yet enabling cytocompatible properties for a certain process window. The differences in Ag content respective Ag release in case of the oxygen based nanocomposites led to different ranges of antibacterial properties (Fig. 5). The lowest $\mathrm{Ag}$ content of $0.03 \mathrm{~g} \mathrm{~cm}^{-3}$ with the lowest $\mathrm{Ag}$ release of $0.19 \mu \mathrm{g} \mathrm{cm}^{-2}$ after $24 \mathrm{~h}$ (in $4 \mathrm{ml}$ bi-distilled water) of the $\mathrm{CO}_{2} / \mathrm{C}_{2} \mathrm{H}_{4} 2: 1-30 \mathrm{~W}$ film was found to be sufficient to kill $P$. aeruginosa, but slightly too low to kill $S$. aureus. The polymer-Ag nanocomposite $\left(\mathrm{CO}_{2} / \mathrm{C}_{2} \mathrm{H}_{4} \quad 2: 1-50 \mathrm{~W}\right)$ with a $\mathrm{Ag}$ content of $0.08 \mathrm{~g} \mathrm{~cm}^{-3}$ and a release of $0.46 \mu \mathrm{g} \mathrm{cm}^{-2}$ after $24 \mathrm{~h}$ turned out to be effective against both bacterial strains. Both coatings were still cytocompatible [29]. All other presented

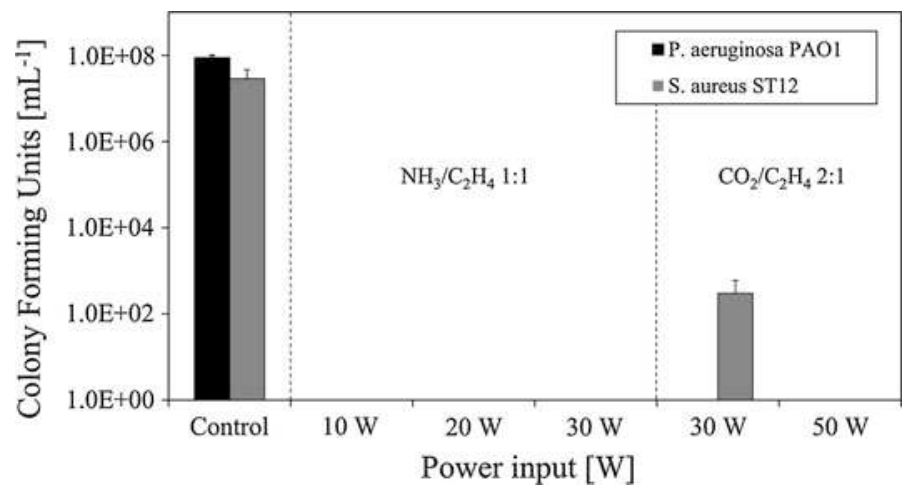

Fig. 5 Antibacterial effectiveness of polymer-Ag nanocomposites against Pseudomonas aeruginosa PAO1 and the gram + strain Staphylococcus aureus (ST12 group) after $24 \mathrm{~h}$ 
plasma coatings were highly effective against the tested strains, but showed cytotoxic effects, as well. The differences in the antibacterial performance of the nitrogen based coatings compared to the oxygen based coatings having almost the same amount of Ag and similar Ag release kinetics can be explained by the differences in the film morphology. The Ag nanoparticles are mainly present in deeper regions of the oxygen based coatings [12], whereas the nanoparticles are more homogeneously distributed over the whole thickness in the nitrogen based coatings [19]. The more homogenous distribution favours a higher Ag ion concentration close to the polymer-Ag nanocomposite surface already shortly after incubation with bacteria or cell solution. No bacteria or cell attachment within the first $24 \mathrm{~h}$ could thus be observed. The $\mathrm{CO}_{2} / \mathrm{C}_{2} \mathrm{H}_{4}$ coatings with the low $\mathrm{Ag}$ content and the deeper lying nanoparticles can be considered as a multilayer film consisting of polymer-Ag nanocomposite with homogeneously distributed $\mathrm{Ag}$ nanoparticles and an ad-layer on top with only randomly distributed nanoparticles yielding a deceleration of the $\mathrm{Ag}$ release. In this case, the cells can attach, which could also be proofed by a multilayer coating design [29].

\section{Conclusion}

Important criteria for the design of antibacterial polymer-Ag nanocomposite coatings are the adjustment of the Ag incorporation, the effectivity (in terms of potential Ag release per incorporated $\mathrm{Ag}$ ), and the time frame of the $\mathrm{Ag}$ release (initial $\mathrm{Ag}$ boost or continuous $\mathrm{Ag}$ release). The Ag release is affected by the plasma polymer properties, e.g. functionality and porosity (film density), as well as the amount of Ag. These coating properties can be adjusted by variation of the gas mixture and the power input as demonstrated by the use of macroscopic kinetics and ICP-OES analyses. A high antibacterial effectiveness as well as a process window, where antibacterial effectivity and cytocompatibility are combined, could be shown due to the adjustability of the polymer-Ag nanocomposite properties as well as the Ag release behaviour. Finally, the morphology of the coatings is a key parameter designing antibacterial yet still cytocompatible coatings.

Acknowledgments Enrico Körner likes to acknowledge Elisabeth Michel and Axel Ritter, Empa St. Gallen, for performing the analytics for the ICP-OES measurements, Patrick Rupper for the XPS analysis and Myriam H. Aguirre, Empa Dübendorf, for the TEM measurements. Peter Cierniak likes to acknowledge Vishwas Kaveeshwar, University of Cologne, for the assistance in performing the antibacterial activity tests. Sections of this work were part of the EU-funded project EmbekI "Development and analysis of polymer based multifunctional bactericidal materials", Grant \#211436 of the seventh framework program.

\section{References}

1. Pang X, Zhitomirsky I (2008) Surf Coat Technol 202:3815-3821

2. Onsuratoom S, Rujiravanit R, Sreethawong T, Tokura S, Chavadej S (2010) Plasma Chem Plasma Process 30:191-206

3. Akhavan O, Ghaderi E (2010) Surf Coat Technol 205:219-223

4. Thomas V, Namdeo M, Mohan YM, Bajpai SK, Bajpai M (2008) J Macromol Sci Part A Pure Appl Chem 45:107-119

5. Travan A, Pelillo C, Donati I, Marsich E, Benincasa M, Scarpa T, Semeraro S, Turco G, Gennaro R, Paoletti S (2009) Biomacromolecules 10:1429-1435

6. Agarwal A, Weis TL, Schurr MJ, Faith NG, Czuprynski CJ, McAnulty JF, Murphy CJ, Abbott NL (2010) Biomaterials 31:680-690

7. Hegemann D, Amberg M, Hanselmann B, Guimond S, Körner E (2011) Biomaterials and plasma processing. Universitatii "Alexandru Ioan Cuza”, Iasi, pp 87-102

8. Hegemann D, Hossain MM (2005) Plasma Process Polym 2:554-562 
9. Hossain MM, Herrmann AS, Hegemann D (2007) Plasma Process Polym 4:135-144

10. Balazs DJ, Hossain MM, Brombacher E, Fortunato G, Körner E, Hegemann D (2007) Plasma Process Polym 4:S380-S385

11. Körner E, Fortunato G, Hegemann D (2009) Plasma Process Polym 6:119-125

12. Körner E, Aguirre MH, Fortunato G, Ritter A, Rühe J, Hegemann D (2010) Plasma Process Polym 7:619-625

13. Körner E, Rupper P, Lübben JF, Ritter A, Rühe J, Hegemann D (2011) Surf Coat Technol 205:2978-2984

14. Wagner HE (2001) Low temperature plasma physics. Wiley-VCH, Berlin, p 305

15. Hegemann D, Hossain MM, Körner E, Balazs DJ (2007) Plasma Process Polym 4:229-238

16. Hegemann D, Körner E, Guimond S (2009) Plasma Process Polym 6:246-254

17. Hegemann D, Körner E, Albrecht K, Schütz U, Guimond S (2010) Plasma Process Polym 7:889-898

18. Hegemann D (2006) Thin Solid Films 515:2173-2178

19. Lischer S, Körner E, Balazs DJ, Shen D, Wick P, Grieder K, Haas D, Heuberger M, Hegemann D (2011) J R Soc Interface 8:1019-1030

20. Strunskus T, Zaporojtchenko V, Behnke K, v. Bechtolsheim C, Faupel F (2000) Adv Eng Mater 2:489-492

21. Schürmann U, Hartung W, Takele H, Zaporojtchenko V, Faupel F (2005) Nanotechnology 16:1078-1082

22. Hariu T (1991) Low temperature epitaxial growth of semiconductors. World Scientific Publishing Co. Pte. Ltd., Singapore

23. Damm C, Münstedt H, Rösch A (2007) J Mater Sci 42:6067-6073

24. Hegemann D, Hanselmann B, Körner E (2011) Plasma Process Polym 8:689-694

25. Guimond S, Hanselmann B, Amberg M, Hegemann D (2010) Pure Appl Chem 82:1239-1245

26. Kawashita M, Toda S, Kim H-M, Kokubo T, Masuda N (2003) J Biomed Mater Res A 66A:266-274

27. Balamurugan A, Balossier G, Laurent-Maquin D, Pina S, Rebelo AHS, Faure J, Ferreira JMF (2008) Dent Mater 24:1343-1351

28. Akhavan O et al (2009) J Phys D Appl Phys 42:135416

29. Körner E, Ritter A, Hanselmann B, Cierniak P, Wiesenmüller S, Bender K, Hegemann D (2012) Plasma Process Polym (in preparation) 